\title{
Show-Me-Careers: Missouri's transition to employment collaborative
}

\author{
Thomas McVeigh*, Amelia Reighard, Arden Day, Derrick Willis, Michelle Reynolds, Ronda Jenson, \\ Jane St. John and Ryan Gee \\ University of Missouri - Kansas City, Institute for Human Development, Kansas City, MO, USA
}

Revised/Accepted April 2017

\begin{abstract}
.
BACKGROUND: The Show-Me-Careers initiative focused on scaling-up and sustaining evidence-based practices that support seamless transitions to integrated employment for youth with intellectual and developmental disabilities (IDD). A Leadership Consortium of systems partners and stakeholders developed six Guiding Principles grounded in current research and best practices regarding transition to integrated employment which provided a framework to identify, expand, and share effective school to work practices.

OBJECTIVE: This article discusses the characteristics and impact of the Show-Me-Careers initiative in Missouri.

CONCLUSION: The principles also allowed the Consortium to review and identify policy, practice, and other changes that were necessary to support the expansion of these practices statewide. The project sought to improve cross-systems strategies to transition within local communities which could be replicated throughout Missouri. In support of this, the Consortium selected eight communities who received funding, technical assistance, and mentoring to scale-up practices related to the Guiding Principles in their communities. The overall approach of the project to address both state and community level systems change was informed by a "Practice Informing Policy-Policy Enabling Practice" framework. The policies and strategies related to the Guiding Principles, implemented by the communities, informed and supported state level change related to transition. Likewise, state level policies and strategies related to the Guiding Principles enabled the implementation of effective community level practice.
\end{abstract}

Keywords: Transition, youth with disabilities, young adults with disabilities, intellectual disability, developmental disability, integrated employment, early work experience, career planning

\section{Background}

Employment rates for individuals with intellectual and developmental disabilities (IDD) at the start of Missouri's Partnerships in Employment (PIE) project was lower than the national average. According to data from the National Report on Employment Services and outcomes, $6 \%$ of individuals with IDD received integrated employment services provided by Missouri's Department of Mental Health (DMH),

\footnotetext{
*Address for correspondence: Thomas McVeigh, University of Missouri - Kansas City, Institute for Human Development, 215 Pershing Road, 5th Floor, Kansas City, MO 64108, USA. Tel.: +1 816235 1750; E-mail: mcveight@umkc.edu.
}

Division of Developmental Disabilities (DD) in 2011 compared with 19\% nationally (Butterworth et al., 2016). This represents only a fraction of the total number of people with IDD statewide. In regards to youth transitioning from high school, 2010 follow-up data from the department of education found that $22 \%$ of Missouri high school students with an Individualized Education Program (IEP) were competitively employed for at least three months in the year after leaving school.

Despite Missouri's employment statistics, there were a number of existing initiatives and resources being implemented at the time which reflected motivation and potential for change. For instance, 
Missouri's State Employment Leadership Network (SELN) working group created a strategic plan focused on increasing the number of individuals with IDD successfully employed in integrated community employment; a Toolkit of Transition Resources for educators, Independent Living specialists, and Vocational Rehabilitation (VR) professionals was being disseminated; an on-line career planning tool was available to transition professionals as a resource to assist youth with career exploration and planning; and 25 Community Transition Teams had already been established to ensure the necessary knowledge and tools to improve post-secondary outcomes were acquired. This array of tools, programs, and resources offered promise; but also highlighted the need to help communities and organizations make sense of the different funding, training, and collaboration opportunities around transition to employment and to put in place systematic ways to coordinate efforts, track progress, and scale up practices that produced the strongest outcomes.

\section{Goals and objectives}

The overall goal of the Show-Me-Careers project was "to scale up and sustain evidence-based practices in Missouri that support seamless transitions to integrated employment." In support of this goal, a Leadership Consortium implemented a comprehensive set of activities to achieve the following objectives.

1. To build cross system and agency collaborations designed to exchange and transfer knowledge and effective practices between partners. The Leadership Consortium jointly developed a statement of Missouri Guiding Principles related to key evidence-based transition to employment practices. The Guiding Principles provided a framework through which to scale-up and evaluate practices related to transition and employment (Miller \& McVeigh, 2012a).

2. To scale-up evidence-based practices within communities through the participation of key partners and groups on a community level (e.g. Community Transition Teams, Missouri VR, Division of DD, schools, employers, self-advocates, families, providers) that demonstrate the effectiveness of model practices. A particular focus of this project was its emphasis on the "scaling-up" of evidence-based practices at the community level. What was needed in Missouri was a collaborative state effort that examined existing practice in relation to the Guiding Principles and created a plan to scale-up effective practices through focused demonstrations, broader implementation, and sustainability. In support of this, transition to employment demonstrations were conducted in eight communities across Missouri.

3. To conduct a review of and make needed changes to collaborative funding options, policies, and procedures that support broader implementation of the effective practices demonstrated within communities. The Leadership Consortium identified and reviewed policies and practices on a statewide basis related to the established Guiding Principles. As a result, a number of community and systems barriers were identified. In addition, community teams supported through the project also identified needed community policy and practice changes.

4. To develop statewide capacity to scale up demonstrations through training, dissemination and broader implementation. Training and technical assistance was provided and products developed and disseminated that were designed to improve knowledge of and capacity to implement the Guiding Principles and evidence-based practices.

5. To evaluate results and to sustain the scaled up practices. Process and outcome evaluations were designed and conducted to provide feedback to support ongoing project improvements. Plans were also developed to sustain the collaboration following grant funding.

\subsection{Consortium and roles}

A Leadership Consortium of state agencies and organizations, listed in Table 1, was formed to provide the overall management and direction for the project. In addition to these core partners, representatives from other agencies, organizations, or stakeholder groups were brought to the table as needed. The Missouri University Center for Excellence in Developmental Disabilities (UCEDD) served as the lead agency and provided staff to support planning, training, coaching, communications, product development and evaluation. This included a project 
Table 1

Show-Me-Careers leadership consortium

UMKC Institute for Human Development (UCEDD, lead organization)

Missouri Developmental Disabilities Council

Missouri Division of Developmental Disabilities

Missouri Division of Workforce Development

Missouri Office of Adult Learning and Rehabilitation

(Vocational Rehabilitation)

Missouri Office of Special Education

Missouri Governor's Council on Disability

People First of Missouri

director who managed the initiative and consultants who provided direct support and coaching to the community pilot sites. In addition, collaboration and communication amongst the Leadership Consortium was strengthened by monthly meetings with discussions that were agenda driven. Annual reports, evaluation data, and visits to community pilot sites provided the Consortium information on system barriers and outcomes.

\subsubsection{Roles related to community level change}

The Leadership Consortium believed that crosssystems collaboration between agencies at the state level were fairly strong, however, much more needed to be done to strengthen collaborations and integration of resources at the community level. For that reason, the project sought to pilot and/or scale-up cross-systems approaches to transition within local communities across the state. The intent of these pilot demonstrations was to facilitate and increase collaboration between systems and organizations working in transition in local communities (i.e. school districts, VR Counselors, DD Support Coordinators, Centers for Independent Living). The Consortium established the framework for the pilot demonstrations and selected eight community teams through a competitive process to receive funding and support. These communities received ongoing training and technical assistance from the Leadership Consortium and project team throughout implementation.

The six Guiding Principles developed by the Leadership Consortium created a common vision across agencies regarding transition to employment and provided a framework through which to identify, expand, and share effective school to work practices. They also allowed the Consortium to review funding and policies and identify barriers that needed to be addressed to support the expansion of evidencebased practices statewide. The Guiding Principles and identified barriers are as follows:
1. Career planning and early work experience: All students should have paid work experiences and participate in high-quality, person-centered career planning. Specifically, the Consortium identified a lack of consistent opportunities for students to access work experience as part of their academic program within school districts or through after school and summer employment.

2. Employer engagement and business partnerships: School-to-career initiatives should engage employers as active partners and should focus on the needs of both businesses and youth. The Consortium identified a need to build relationships with employers and educate the business community about the benefits of hiring people with disabilities and the assistance available regarding any necessary accommodations and supports.

3. involvement: Families should be encouraged and equipped to have high expectations for their child's future and to participate actively in all parts of transition planning. The Consortium saw a need to raise awareness and expectations of parents regarding integrated community employment as a desired and feasible outcome.

4. Integration of systems: School-based and post- school service systems should coordinate efforts to make sure students can move seamlessly from school to career. The Consortium acknowledged a need to improve integration of resources between systems especially at the community level.

5. Post-secondary education and training: Students with IDD should get the support they need to aim for, apply to, enter, and succeed in post-secondary education/training. The Consortium saw a need to promote post-secondary education and training as a viable option for students with IDD and educate agencies, schools, and families about the post-secondary options throughout the state.

6. Youth development: Students should have the opportunity to build self- determination skills and community connections. The Consortium identified a lack of opportunities for students with IDD to build self-determination, social capital, and employment-related skills to become qualified candidates for integrated employment. 


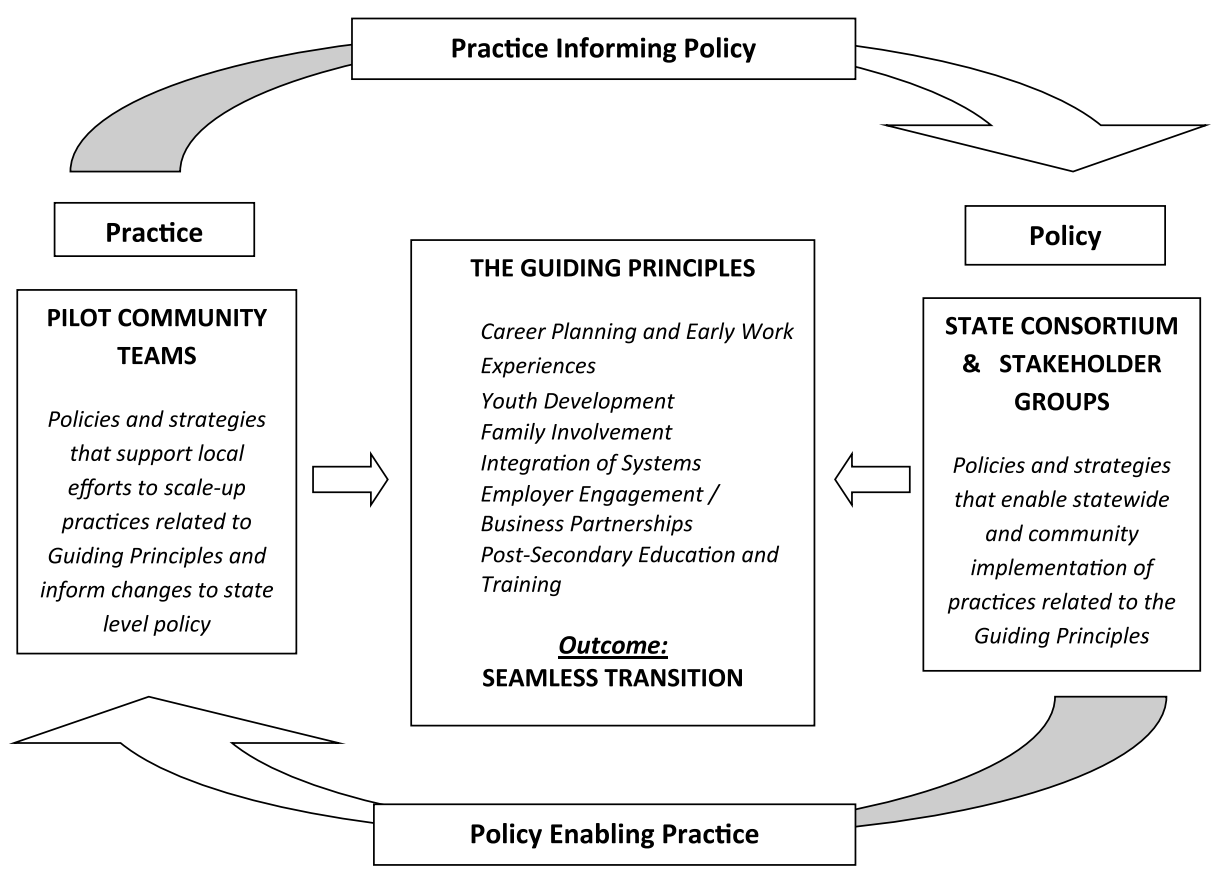

Fig. 1. Policy-Enables-Practice/Practice-Informs-Policy Framework.

\subsubsection{Roles related to state level change}

The Leadership Consortium adopted a "policyenables-practice/practice-informs-policy" framework shown in Fig. 1. The policies and strategies related to the Guiding Principles, which were implemented by the pilot communities, would inform and support state level policy change related to transition. Likewise, state level policies and strategies related to the Guiding Principles would enable the implementation of effective community level practice. Efforts at both the community and state level would lead to the overall outcome of seamless transition to employment for youth with IDD. As an example, at the onset of the project, a barrier was identified by a community partner related to delays and gaps in applying for and receiving Medicaid for youth as they turned 18. In response to this concern raised by pilot communities, the Division of Developmental Disabilities (DD) and the Family Support Division within Social Services developed a new protocol allowing the Medicaid application to be submitted up to 90 days prior to a student's 18th birthday. This was done to reduce gaps and delays in services at the time of transition.

In light of this framework, state agency representatives participating on the Leadership Consortium contributed to individual changes in their own agency's organizational policies. In addition, the multi-agency collaboration of the Consortium allowed agency representatives to gather input and feedback from each other on systems change projects, statewide training opportunities, and other initiatives. For example, the Division of DD developed a draft Individual Support Plan Guide that provides an overview of person-centered planning process requirements and the creation of the Individual Support Plan. This guide includes a section related to transition planning and employment. This guide was reviewed by Consortium members and recommendations were provided to the Division of DD.

\subsection{Work plan elements}

To achieve the project goal and objectives the following work plan elements were implemented.

\subsubsection{Community pilot sites}

It was decided by the Leadership Consortium that collaborative teams in eight pilot communities would be selected through a competitive application process. These community teams received funding and support over a period of $31 / 2$ years to scale-up practices related to transition to employment within their communities. The Consortium developed a Request for Proposal process and solicited applications from community teams across the state. In support of this, 
the Project Director conducted nine pre-application meetings across the state to provide community teams information about the project Guiding Principles and the objectives of the community mini grants. In addition, the Consortium developed a Planning Guide that could be used by community teams to conduct a community self-assessment in relation to the Guiding Principles, and to identify priorities to be addressed within their communities. Pilot communities were to develop a core team of cross-agency partners to plan, implement, and evaluate activities aimed to support the following outcomes:

\section{Intended Short Term Outcomes:}

- Increased collaboration and coordination of resources at the community level that supports access to early work and inclusive employment opportunities for youth with IDD.

- Increased number of businesses providing early work experiences and/or inclusive employment to youth with IDD.

- Increased number of youth and young adults with IDD who explore work and career preferences and opportunities through participation in a variety of early community work experiences.

\section{Intended Long Term Outcome:}

- Increased number of youth with IDD who transition seamlessly upon high school graduation to inclusive employment and/or post-secondary education and training.

To achieve these outcomes, selected pilot communities were asked to use the project's Guiding Principles as a framework to guide their efforts. Through the planning process, communities were able to focus more attention on those Principles most relevant to their community needs and goals. In addition to the Guiding Principles, communities may have chosen to focus on additional barriers to inclusive employment identified within their local area. For example, transportation and the fear of losing benefits were obstacles for many communities.

The selected pilot sites consisted of cross-agency partnerships that included, but were not limited to, school district personnel, district VR counselors, Division of DD youth transition/employment coordinators, Centers for Independent Living staff, Career Center staff, employment providers, local Chambers of Commerce representatives, family members, and individuals with IDD.
Pilot sites provided an annual report describing the initiatives of their community team, ongoing challenges to be addressed, and future work plans. The project director, community consultants, and Consortium members also conducted periodic site visits to discuss the progress made and barriers identified in each community. In addition, each pilot site submitted data to be compiled by the project evaluation team on data elements required for the PIE evaluation conducted by the Lewin Group. This included community level data such as the number of employers hiring individuals with IDD and individual level data such as the number of individuals participating in employment programs/classes, on-the-job training, internships, and paid employment.

\subsubsection{Capacity building initiatives}

A goal at the start of the project was to increase opportunities for the exchange and transfer of knowledge and effective practices between partners and throughout Missouri. In response to this, capacity building initiatives were implemented both at the community and state levels throughout the project. At the community level, pilot communities received funding, technical assistance, and coaching to build the capacity of the community team to implement their work plan. Such activities included participating in monthly webinars, topic specific training events, annual site visits, and the annual Show-Me-Careers Leadership Institute held for all pilot sites. These activities also facilitated the exchange of knowledge and effective practices between the Consortium and pilot sites and from pilot to pilot. Following are descriptions of these capacity building initiatives.

Show-Me-Careers hosted a total of four annual Leadership Institutes where pilot communities received training in areas related to the Guiding Principles. Various Consortium members and additional content experts delivered training on topics such as enhancing family involvement, developing and maintaining business partnerships, creating early work experiences, and blending and braiding funding. Pilot sites were also provided a platform to share their effective practices with each other during these Institutes.

Teams were also supported to attend additional trainings on transition offered throughout the state. For instance, pilot site teams were sponsored to attend the Department of Elementary and Secondary Education's (DESE) annual Transition Training Institute, where multi-agency teams comprised of school personnel and partners from various state agencies 
and community organizations attended topic-specific content sessions and multiple facilitated team planning times to develop a community-based action plan. During these Training Institutes, members of the Leadership Consortium, project staff, and representatives from the pilot sites were asked to present at breakout sessions on topics such as business-provider relationships, community-school partnerships, family engagement strategies, and youth development curriculums.

Pilot sites also received targeted training, technical assistance, and coaching throughout the project. For example, partners such as the Greater Kansas City Business Leadership Network and the Missouri Family-to-Family Resource Center, were brought in to provide targeted training and technical assistance in areas related to increasing family engagement and building business partnerships which were two priority areas of the project. In addition, two consultants were selected to work individually with pilot communities to provide assistance and guidance in developing and executing annual work plans. For instance, one consultant provided training to some pilot sites on a career discovery curriculum that was later embedded into one school's career center services. Technical assistance was also given through a monthly webinar series based on the project Guiding Principles. The focus for the webinars was increasing collaboration between the pilot communities who were able to hear about and discuss the work plans and initiatives of other communities. Ongoing feedback from the communities informed further webinar and technical assistance topics.

As part of their work plans, pilot sites also hosted trainings to enhance the capacity of professionals and others in their community. Such trainings included business trainings on hiring individuals with a disability; job coaching and supports training for area school districts and agency personnel; and, training professionals, teachers, self-advocates, and families on use of the LifeCourse framework and tools within their organizations.

On the state level, Consortium members collaborated on a number of statewide training efforts. For example, a need was identified to assure that families, educators, and others have ready access to benefits information and supports. In addition, there was a need to educate and provide support to families regarding building assets. To address these needs, the project co-hosted a statewide asset development workshop, "Achieving the American Dream" Financial Stability Summit, for self-advocates and their families in partnership with the Missouri Developmental Disabilities Council and National Alliance on Mental Illness (NAMI). In addition, Show-MeCareers collaborated with the Missouri Developmental Disabilities Council and others to train certified benefits specialists across the state. Several pilot sites sent representatives to these trainings.

Consortium expertise and knowledge was also built through local and national trainings. Consortium members attended conferences and trainings such as the National Business Leadership Network Conference, SELN meetings, and both state and National Association of People Supporting Employment First (APSE) conferences.

\subsubsection{State and community policy and practice changes}

At the start of the project, the Consortium reviewed data about policies and practices from several sources to identify priority areas for change efforts in Missouri. As a PIE grantee, stakeholders in Missouri completed a comprehensive survey and self-evaluation that provided an analysis of the state's infrastructure for achieving the project's goals. Representatives from the Consortium agencies, business representatives, and other stakeholders participated in a meeting to discuss survey findings and potential focus areas for improvement. Some recommendations that emanated from the initial assessments included developing resource materials for families, developing standardized training expectations for employment staff, engaging Missouri Career Centers to enhance their support of youth and young adults as they transition from school to adult work life, and developing core expectations for collaborative community teams supporting transitions.

Additional sources of data included data gathered from state and community sources; Consortium meetings held with the pilot sites to discuss the barriers and challenges experienced at the community level; a Levels of Collaboration survey completed by Consortium and community members and structured around the Guiding Principles; and, the Institute for Community Inclusion's (ICI) High Performing States (Hall et al., 2007) indicators. These activities helped identify barriers related to the Guiding Principles previously mentioned.

\subsubsection{Use of systems and community level evaluation data and rubrics}

All communities, as well as the state level Consortium leading the project, participated in the project 
evaluation. The evaluation was structured to track progress on the Guiding Principles (described above) as well as the systems-level change which is aligned to the High Performing States Framework developed by ICI. The core components of systems-level change that we tracked through the evaluation included: Strategic Goals and Operating Policies, Leadership, Funding Mechanisms, Training and Technical Assistance, Interagency Collaboration and Partnerships, Services and Service Innovations, and Performance Measurement and Data Management (Hall et al., 2007). Using a rubric style evaluation that included outcome indicators and displays levels of implementation, community and state level data were collected and plotted on a rubric. The purpose of the rubrics was to provide a structure for reflecting on, documenting, and revisiting the status of current practices. Data to inform the rubrics was collected through state and community level surveys. The surveys were administered annually and plotted in state and community data profiles. The state Consortium and local pilot communities discussed and reflected on the data profiles and used this information to support ongoing systems and community planning.

\subsubsection{Description of new products}

Throughout the project, various products were developed by project staff in collaboration with the Leadership Consortium and other stakeholders. The products served as a resource both for pilot community teams as well as others across the state. The products are described below.

As mentioned previously a Show-Me-Careers Planning Guide was developed as a planning tool to be used as a part of the competitive application process for pilot sites (Miller \& McVeigh, 2012b). It was designed to help applicants reflect on the state of transition services in their defined communities and discuss potential approaches to overcoming barriers and/or scaling-up successes that lead to a more seamless transition for youth and young adult with IDD. Eventually, the guide was reformatted to be useful to any collaborative team or community. The reformatted version was presented and disseminated at the Missouri DESE Transition Institute and the National PIE network meeting.

A significant initiative of the project was a collaboration with the Missouri Family-to-Family Resource Center and the National Community of Practice for Supporting Families of Individuals with Intellectual and Developmental Disabilities. Show-Me-Careers collaborated with these groups to implement a range of planning and capacity building initiatives related to improving family engagement in transition. In support of this, a new product called Charting the LifeCourse: A Guide for Daily Life and EmploymentTransition Age (Reynolds et al., 2015) was developed to meet the needs of individuals with disabilities and families who are navigating the transition path. The packet provides a framework for transition planning that can be used by professionals, teachers, support persons, or individuals with their families. The packet was launched at an annual Show-MeCareers Leadership Institute to be tested with the project's pilot sites. Since then over ten thousand guides were disseminated through state and community partners. Trainings in the use of the guides have been conducted across the state to a variety of stakeholders including school personnel, support coordinators, Pre-employment Transition Specialists and Missouri VR counselors. Some Missouri school districts have embedded the guide into their curriculum and teachers see it as a tool that can help them better serve their transitioning students. This resource also includes video guidance that was developed to help individuals and their support persons, whether a family member or support staff, understand how to use the packet to discuss future employment expectations and plans.

Additional products include the Show-Me-Careers website that served as a repository of both local and national practices and resources related to the core Guiding Principles; a booklet of labor market data from each county across the state, which were compiled into a product disseminated to community teams; evaluation briefs that were disseminated to the Consortium and community teams; and the results of community conversations with pilot communities regarding effective practices and barriers related to the project Guiding Principles which were developed and disseminated. These products were made available to the pilot community team members, the Leadership Consortium, and additional key stakeholders.

\subsection{Outcomes}

The initiatives of the project were designed to produce outcomes at the state, community, and individual levels. Policy, practice, and systems changes at the state and community levels that support improved access to employment led to more engagement in employment activities and participation 
in integrated employment for individuals with IDD.

\subsubsection{Policy, practice, and systems changes at the state level}

Show-Me-Careers Consortium representatives were involved in numerous initiatives across Missouri that support increased access to employment. Though these initiatives are not necessarily a direct result of Show-Me-Careers, they demonstrate a commitment and support to state level change by project partners and others. The following are a few examples of policy and practice changes initiated or supported by state partners that occurred during the five years of the project.

\subsubsection{Missouri Vocational Rehabilitation (VR)}

Missouri VR allocated funding to support Preemployment transition services to Missouri public school students with disabilities, ages 16-21, who are potentially eligible for vocational rehabilitation services. These services are designed to make an impactful difference for more students with disabilities at an earlier age which will lead to better coordination, enhanced communication, stronger collaboration, and increased successful post-school outcomes. The program was made possible through legislative changes in the Workforce Innovation and Opportunities Act (WIOA) and focuses on providing hands-on supports by working directly with students, families and schools. Twenty-one specialists from around the state began offering services in five areas: job exploration; work-based learning; counseling for post-secondary education; workplace readiness; and, self-advocacy and peer mentoring. The start of this new initiative coincided with the development of the Charting the LifeCourse: A Guide for Daily Life and EmploymentTransition Age (Reynolds et al., 2015) which provided a tool for the specialists to use with students in school and families. In addition, the specialists collaborated with the Show-Me-Careers pilot sites.

Missouri VR also allocated funding to develop an initiative to support new summer work experience programs. In partnership with participating Community Rehabilitation Programs and Independent Living Centers, Missouri VR offered a paid summer work experience opportunity for VR eligible students with disabilities who have not yet graduated from high school. In 2016, 541 students participated in a summer work experience at 144 different places of employment. The students represented 164 different high schools in the state.

\subsubsection{Missouri Division of Developmental Disabilities (DD)}

In 2014, the Missouri Division of DD and Missouri VR put in place a MOU as a guide to increase collaboration and coordination of services for the persons they serve. This partnership was viewed as a necessary step to ensure seamless service delivery and to maximize long term employment retention for their consumers. In addition, through the Office of Disability Employment Policy's Employment First State Leadership Mentoring Program (EFSLMP), a new MOU has been developed between multiple state agencies.

Several policy changes occurred over the course of project within Missouri Division of DD such as a new minimum training and continuing education requirement for DD employment service providers, training of service coordinators on Service Plan Guidelines that include requirements for transition, and a protocol allowing the Medicaid application to be submitted up to 90 days prior to a student's 18 th birthday which will reduce gaps and delays in services at the time of transition. Show-Me-Careers also worked with the SELN and Missouri Division of DD on efforts to build capacity and competencies of support coordinators and to address issues related to work and benefits.

\subsubsection{Missouri Division of Workforce Development (DWD)}

Missouri DWD responded to a need in some rural areas for Job Center services to be delivered in the classroom rather than solely in the Job Center. Job Center staff traveled to school districts on multiple occasions where students were provided with a wide array of Job Center services throughout the school year. These ongoing services allowed students to improve their work skills while still attending high school. Students were able to access the workforce system services that continue to be available to them as adults. This need was identified and developed through a Show-Me-Careers pilot site collaboration. In addition, pilot sites that collaborated with DWD were able to refer youth with IDD and other disabilities to the WIOA Youth Program where they were able to access paid work experiences. Several of these paid work experiences have led to permanent employment.

\subsubsection{Missouri Developmental Disabilities Council}

The Missouri DD Council partnered with the Greater Kansas City Business Leadership Network 
to develop a web-based business resource site (http://shift.gkcbln.org). This site was developed by and for employers to promote the hiring of qualified job seekers with disabilities. The overall goal of the initiative was to create an online, one-stop resource for Missouri businesses to access information, education, and resources to enhance their diversity and inclusion practices, especially as it pertains to outreach, hiring and including people with disabilities in their workforce. In addition, the DD Council included funding in its new five year plan to support the development of three new Business Leadership Networks in local communities across the state. A business group in one Show-Me-Careers pilot community applied and was awarded the funding.

\subsubsection{University of Missouri-Kansas City, Institute for Human Development (UMKC-IHD)}

Show-Me-Careers collaborated with the Missouri Family-to-Family Resource Center, a center within UMKC-IHD, to develop and evaluate the previously described Charting the LifeCourse: A Guide for Daily Life and Employment- Transition Age (Reynolds et al., 2015). The Show-Me-Careers evaluation team conducted a preliminary qualitative evaluation of the guide which was designed to meet the needs of individuals with disabilities and families navigating the transition path. Support coordinators from pilot sites and Pre-Employment Transition Specialists using the tools with families and individuals with IDD were interviewed about the utility and effectiveness of the guide. Information gathered from the evaluation has been used to further refine the tool as well as to better understand how to train professionals and families to use the tools. The Missouri Family-to-Family team continues to share the guide with local and national stakeholder groups such as the National Community of Practice for Supporting Families of Individuals with Intellectual and Developmental Disabilities which now has 17 participating states. Some Community of Practice states have shown great interest in incorporating the employment guide in the work of state developmental disability systems, family organizations, schools and employment specialists.

\subsubsection{State level surveys and rubrics}

Data were collected at the state and community level at three time points, beginning in the second year of the project: (1) baseline at the beginning of the second year of funding; (2) during the third year of funding; and (3) during the last year of funding. Changes in agency practices that were made at the state level are reflected in the State level survey and rubric data. At the beginning of the project a rubric was developed that included both System (High Performing States) and Practice (Guiding Principles) indicators. Four Consortium member state agencies completed surveys addressing both systemslevel changes and pertinent day-to-day practices of their agencies. During the second and third data collection periods of the project, Consortium members were asked to complete their surveys with a team of people from their organization in order to obtain a more complete representative picture, as well as encourage discussion within the organization about the topics addressed. Data from these two data points was analyzed by looking at improvements made over time, as well as comparing the data to an $80 \%$ benchmark of agreement that measured whether the practice was being implemented either partially or extensively. An $80 \%$ benchmark was established because it is both high enough to show an agreement of the majority, while also allowing for some flexibility and differences due to various factors. The benchmark provided a goal to work towards, as well as a measure for how well we were doing in certain areas. After receiving, compiling, and graphing the state-level data and comparing it to the benchmark, the Consortium would meet to discuss if the data confirmed what they already knew about what was happening in the state, whether or not the data was surprising, and what could be concluded about what was and was not working. This conversation also included a discussion of how the Consortium would use this information to prioritize action.

Results of the survey are listed in Table 2. Areas in which the $80 \%$ benchmark was met are marked. While these changes were not statistically significant, in part due to the very small sample size, it did give the Consortium an opportunity to have specific and targeted cross-organization conversations about both their data and the progress that was being made.

The $80 \%$ benchmark was met on some items, but did not necessarily improve over the course of the project, indicating areas in which the Consortium agencies were already excelling. Overall, according to the survey data, improvements were noted in 9 areas, remained the same in 1 area, and showed decreases in 3 areas. These are also marked in Table 2. With the exception of Performance Measurement and Data Management, which included items on sharing 
Table 2

State level results

\begin{tabular}{|c|c|c|}
\hline & $\begin{array}{c}\text { Time } 2(n=4 \\
\text { agencies })\end{array}$ & $\begin{array}{c}\text { Time } 3(n=4 \\
\text { agencies })\end{array}$ \\
\hline \multicolumn{3}{|l|}{ High Performing States Indicators } \\
\hline Strategic Goals and Operating Policies & $75 \%$ & $50 \%$ \\
\hline Leadership & $63 \%$ & $71 \%$ \\
\hline Funding Mechanisms & $75 \%$ & $67 \%$ \\
\hline Training and Technical Assistance ${ }^{\circ \circ}$ & $75 \%$ & $100 \%$ \\
\hline Interagency Collaboration and Partnerships ${ }^{\circ \circ}$ & $75 \%$ & $86 \%$ \\
\hline Services and Service Innovations ${ }^{\circ \circ}$ & $88 \%$ & $100 \%$ \\
\hline Performance Measurement and Data Management & $50 \%$ & $33 \%$ \\
\hline \multicolumn{3}{|l|}{ Guiding Principles Indicators } \\
\hline Career Planning and Early Work Experiences ${ }^{\circ \circ}$ & $75 \%$ & $100 \%$ \\
\hline Youth Development ${ }^{\circ}$ & $75 \%$ & $100 \%$ \\
\hline Family Involvement ${ }^{\circ}$ & $75 \%$ & $100 \%$ \\
\hline Integration of Systems ${ }^{\text {circo }}$ & $75 \%$ & $100 \%$ \\
\hline Employer Engagement/Business Partnerships ${ }^{\circ}$ & $100 \%$ & $100 \%$ \\
\hline Post-Secondary Education and Training ${ }^{\circ \circ}$ & $75 \%$ & $100 \%$ \\
\hline
\end{tabular}

data systems across state agencies, the Consortium results were close to the $80 \%$ benchmark on most items.

\subsubsection{Community level surveys and rubrics}

Pilot communities also completed surveys addressing both systems-level changes and day-to-day practices, in the form of Guiding Principles. Pilot communities were encouraged to send the survey to as many community members involved in their project as needed to get a representative picture of their community and their projects' impact. Data was again analyzed by looking at improvements made over time, as well as comparing data to an $80 \%$ benchmark to reflect actions that were in place or partially in place at the pilot community level. Areas in which the pilot communities both made improvements, and met the benchmark of $80 \%$ agreement in the last year are marked in Table 3. In this table, areas in which the pilot communities did not meet the $80 \%$ benchmark, but still made statistically significant improvements are also marked.

Pilot communities made statistically significant improvements but did not meet benchmarks in the area of Career Planning and Early Work Experiences, indicating overall improvement with some room for growth. They made statistically significant improvements and met benchmarks in four areas: Post-secondary Education and Training, Youth Development, Family Involvement, and Business Engagement. Finally, pilot communities met benchmarks on all of the high performing states indicators, but only showed non-significant improvements in
Funding Mechanisms, Training and Technical Assistance, and Interagency Collaboration.

\subsubsection{Changes at the individual level}

Data was also collected from each of the pilot communities on a sample of students that were followed through the project. Over the course of this project, data were collected on 429 students. Through this same mechanism, there was some community-level data collected on the numbers of employers involved in the project.

Overall, in the communities involved in this project, there were increases in the percent of students who held part-time jobs (12\% to 33\%) and who had paid work experiences ( $7 \%$ to $20 \%$ ). While the percent of paid work experiences increased, the percent of unpaid work experiences stayed about the same, indicating a priority for the pilot communities to get students paid work experiences.

In addition to some of these student-level outcomes, the number of employers engaged with communities also increased, including increases in the number of employers hiring students with I/DD (22 to 40) and those employers providing paid work experiences (4 to 32). Also, a relatively high correlation $(r=0.75)$ was found between the number of employers hiring pilot community participants and the percent of students with part-time employment.

\subsection{Sustainability}

Leadership Consortium members were in agreement that the key to sustaining state level efforts was 
Table 3

Pilot community results

\begin{tabular}{|c|c|c|c|c|c|}
\hline & \multicolumn{2}{|c|}{ Time $1(n=72)$} & \multicolumn{2}{|c|}{ Time $3(n=38)$} & \multirow[b]{2}{*}{$t$-test } \\
\hline & Mean & $\begin{array}{c}\text { Standard } \\
\text { Deviation }\end{array}$ & Mean & $\begin{array}{c}\text { Standard } \\
\text { Deviation }\end{array}$ & \\
\hline \multicolumn{6}{|l|}{ Guiding Principles Indicators } \\
\hline Career Planning and Early Work Experiences & 2.70 & 0.65 & 3.07 & 0.57 & $-3.19^{*}$ \\
\hline Integration of Systems & 2.87 & 0.75 & 3.27 & 0.55 & -3.06 \\
\hline Post-Secondary Education and Training ${ }^{\circ}$ & 3.03 & 0.72 & 3.49 & 0.68 & $-3.31^{*}$ \\
\hline Youth Development ${ }^{\circ}$ & 3.00 & 0.76 & 3.35 & 0.54 & $-2.57^{*}$ \\
\hline Family Involvement ${ }^{\circ}$ & 2.80 & 0.70 & 3.32 & 0.54 & $-4.02^{* *}$ \\
\hline Business Engagement ${ }^{\circ}$ & 2.71 & 0.78 & 3.21 & 0.66 & $-3.39^{*}$ \\
\hline
\end{tabular}

Note: *denotes $p<0.01$ significance level. ** denotes $p<0.001$ significance level.

denotes areas where an $80 \%$ benchmark was met.

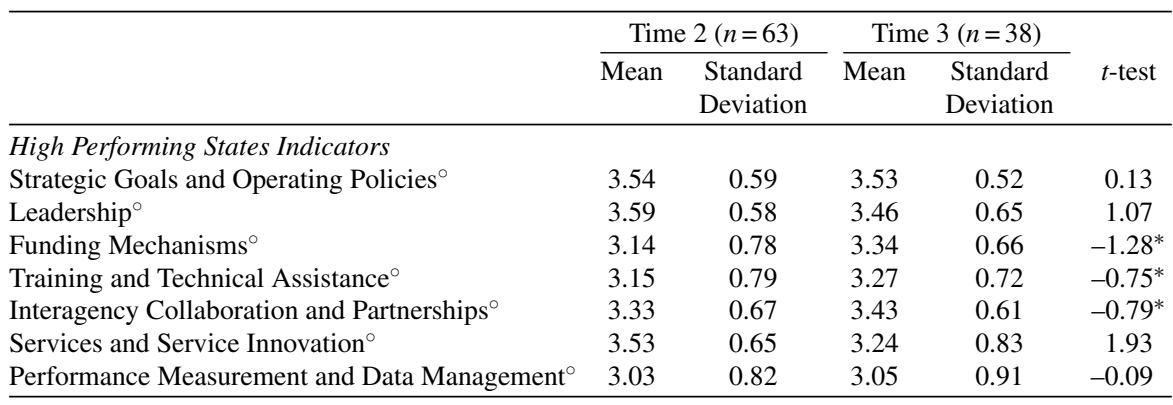

Note: ${ }^{*}$ denotes areas where there was improvement but no statistically significant change. ${ }^{\circ}$ denotes areas where an $80 \%$ benchmark was met.

in maintaining the cross agency collaborations that guided the work of the project. There were many discussions about the development of a new state level employment work group, but in the end it was decided that an existing structure that could incorporate new and evolving partnerships would be ideal. It was determined that a natural fit for these collaborations would be the Missouri State Employment Leadership Network (SELN) working group, which is led by the Missouri Division of DD. Key leaders of the Missouri SELN that participated on the ShowMe-Careers Consortium utilized the Consortium in an advisory capacity to discuss SELN employment initiatives and state level systems change during the project. The SELN will prioritize Show-Me-Careers initiatives that were started but not completed within the project period. For instance, a survey was conducted with pilot sites regarding work incentives and access to benefits planning information. The results of the survey are guiding the development of cross agency publications sharing a consistent message regarding how individuals are better off working, deflecting misinformation about work and benefits, and providing basic information on how work incentives are a tool for increasing earning and available benefits. This publication will be a priority of the
SELN in the next year. All of the agencies who currently serve on the Show-Me-Careers Consortium will select members to represent their organizations on the SELN Leadership Team which will begin meeting in early 2017. The focus of this new group will also be on promoting integrated employment for individuals but will expand its focus to address the needs of adults as well as youth with IDD.

Plans to sustain the project efforts at the community level have been made by each pilot site. Some communities will integrate the work of Show-MeCareers into other existing transition team efforts. These transition groups are ideal for sustaining a cross-systems collaboration and approach to transition. Business partnerships will continue to grow through community employment consortiums and continued involvement in local business groups such as Chambers of Commerce and Rotaries. One community was awarded Missouri DD Council funding to establish a new Business Leadership Network. In order to sustain isolated activities (i.e. transition fairs, youth development classes, trainings, etc.), pilot sites are looking within their collaborations for funding opportunities. One community is utilizing their County DD Board to provide funds to hold bi-annual special education teacher trainings 
in transition. Another community is partnering with other community groups to continue to provide youth development classes and transition fairs within local school districts. All pilot sites expressed a desire to maintain the collaborations that developed because of Show-Me-Careers and expand to include additional partners such as the increased involvement of Workforce Investment Boards. For example, one community consortium that included three school district partners has formed a coalition called the Northland Career Connections and developed a plan to expand their efforts.

In addition to the efforts of the consortium and pilot sites, work experience opportunities throughout the state will continue to be sustained through new funding mechanisms. As previously mentioned, changes in WIOA led to a Missouri VR initiative to support summer work experience programs. Several ShowMe-Careers pilot sites have participated in the first two years of funding and have plans to sustain these efforts in the future.

\subsection{Lessons learned and promising practices}

Near the end of Show-Me-Careers, the project director and staff used evaluation data, reflections from pilot site focus groups, and reflections from the Consortium members to capture the lessons learned related to the project Guiding Principles.

\subsubsection{Regarding community collaborations and partnerships}

The project found that a small amount of funding could provide the impetus for a diverse group of individuals to come together and set common goals with plans to address those goals. The partnerships which were formed were essential to the work plan set forth by the communities and set them up for sustainability. An important component of collaboration was understanding what each partner was able to bring to the table and the specific roles each agency or organization plays in the transition process. This understanding strengthens relationships which leads to joint problem solving and sharing of resources. In order to keep moving the collaboration ahead, pilot sites found that frequent communication was key. This was often facilitated by a "champion" within the partnership that continued to move the work in a positive direction, a champion who had the social capital to engage partners. It also takes time for relationships to grow. Over time individuals felt less "siloed" and that they had the ability to make things happen as part of the collaboration. As partnerships grew, there was a corresponding shift in the belief systems of some partners away from values of protection and segregation towards inclusion and self-determination. In addition, partnerships thrived when there was room to continually evolve, allowing for new partners to emerge throughout the project. Finally, a key component to promoting community change was the coaching and resources provided by the community consultants. Community groups need access to individuals who can help problem solve and connect them to state resources. The work of the consultants was also enhanced through the development of a state level Community of Practice through opportunities such as the monthly webinars and annual Leadership Institutes which provided forums for the ongoing exchange of information.

\subsubsection{Regarding work experiences and joint school/community initiatives}

Numerous pilot sites created joint initiatives such as career classes, job clubs, and work experience sites, between schools and community providers or independent living centers. These initiatives through community partners provided additional resources to schools that often lack the means to implement work-based learning opportunities for their students. Schools began to understand what other partners could provide and saw them as a positive resources. In addition, funding for summer work experiences provided an opportunity for schools and community agencies to collaborate and enhance work experience opportunities. As a result of increased collaboration and funding, some schools reported more openness among administrators to support work experience programs. Pilot sites also sought to address barriers to work experiences through their collaborations. For example, transportation to work sites has consistently been identified as a challenge in communities. To address this, one community's county board provided funding for transportation to sites. Additional assistance in addressing barriers and streamlining collaborations at the community level came through ongoing training and technical assistance opportunities that supported capacity building amongst schools and their partners.

\subsubsection{Regarding business partnerships}

When it came to engaging businesses, some of the more productive strategies among pilots included working with businesses to develop job shadowing or work experience sites. In addition to providing 
experience for youth, it provided an opportunity for new businesses to bring individuals with disabilities into their business without a long term commitment. Many times these work experiences were leveraged into ongoing employment opportunities and longer term partnerships formed with the business. Many pilot sites also found it was helpful to be active members of Rotary, Chambers, and other business groups as a way to begin to develop new personal relationships. Due to an increasing interest from workforce development to partner in providing supports to individuals with disabilities some pilot sites were able to work with their local career center. Despite great strides pilot sites made in engaging businesses, it was sometimes challenging to engage business as a member of their community collaborative. When it was done successfully, it proved to be very beneficial to forming connections to other employers.

\subsubsection{Regarding family support}

As pilot sites began to engage families in the transition process, they found many parents had low or no expectations about their child being employed postgraduation. It seemed apparent that the discussions around employment with families needed to start earlier, as early as elementary school. It was also found to be easier to engage with families when their children are younger. As children age it also seemed more difficult to connect with families. There seemed to be an openness and consensus from community partners to begin working with individuals at an earlier age. Pilot sites also reported a need to focus on soft skills at an early age and development of social networks for youth.

\subsubsection{Additional lessons learned related to promoting practice and systems changes}

Changes at the federal level can have significant impact on state change. For instance, the Workforce Investment Opportunity Act and Home and Community-Based Services rule greatly influenced the development of new work experience opportunities for youth. These and other changes on the federal level have provided the impetus for new changes (e.g. summer work programs) and accelerated a movement away from segregated day services.

\section{Conclusion}

Show-Me-Careers was one of many initiatives in Missouri making contributions in the areas of transition and integrated employment for people with disabilities in Missouri. These synergistic efforts as a whole have contributed to a gradual increase in employment rates for individuals with IDD. According to the National Report on Employment Services and Outcomes, the percentage of people participating in integrated employment services increased from $6 \%$ in 2011 to $12 \%$ in 2014 (Butterworth et al., 2016). In regards to youth transitioning from high school, 2015-2016 follow up data from the Department of Education found that almost $37 \%$ of graduated students with an IEP were competitively employed compared to $22 \%$ in 2010 . An additional $33 \%$ were enrolled in post-secondary education or training programs (DESE, 2016). Though much has been accomplished there remains much work yet to do. State and community collaborations through leadership groups such as the Missouri SELN and others are poised to continue this work and use the lessons learned and outcomes of this project to advance employment opportunities for individuals with IDD and other disabilities in Missouri.

\section{Acknowledgments}

Show-Me-Careers was funded through a grant by the U.S. Department of Health and Human Services, Administration for Community Living, Administration on Intellectual and developmental Disabilities (AIDD), grant no. 90DN0288.

\section{Conflict of interest}

None to report.

\section{References}

Butterworth, J., Smith, F. A., Winsor, J., Ciulla Timmons, J., Migliore, A., \& Domin, D. (2016). StateData: The national report on employment services and outcomes. Boston, MA: University of Massachusetts Boston, Institute for Community Inclusion.

Hall, A. C., Butterworth, J., Winsor, J., Gilmore, D. S., \& Metzel, D. (2007). Pushing the employment agenda: Case study research of high performing states in integrated employment. Intellectual and Developmental Disabilities, 45(3), 182-198.

Miller, C., \& McVeigh, T. (2012a). Show-Me-Careers Missouri's transition to employment collaborative: Guiding Principles. Retrieved from http://showmecareers.org/user_storage/ File/Guiding\%20Principles\%20Revised\%201-29-15.pdf 
Miller, C., \& McVeigh, T. (2012b). Show-Me-Careers Missouri's transition to employment collaborative: Planning Guide. Retrieved from http://showmecareers.org/user_storage/File/ SMC\%20PLANNING\%20GUIDE\%20Revisions $\% 20$ for $\% 20$ Transition\%20Instititue\%206-7-13.pdf

Missouri Department of Elementary and Secondary Education [DESE]. (2016). Special Education State Profile. Retrieved 1/10/2017 from https://dese.mo.gov/sites/default/files/se-dataspecial-education-state-profile.pdf
Reynolds, M., St John, J., \& Hiles, R. (2015). Charting the LifeCourse: A Guide for Daily Life and EmploymentTransition Age. Kansas City, MO: Missouri Family-toFamily, Institute for Human Development, University of Missouri Kansas City. http://www.lifecoursetools.com/wpcontent/uploads/EMPLOYMENT-GUIDE-FINAL.pdf 